\title{
In-situ Stress Measurement and Application of NJ Project in Pakistan
}

\author{
Kaihua Zeng ${ }^{1, a}$, Kaikai Wang ${ }^{1, b, ~}{ }^{*}$, Hongtao Dai ${ }^{1, c}$, Xiaochuan Han ${ }^{1, d}$ \\ ${ }^{1}$ Nanchang institute of Technology, Nanchang 330099, Jiangxi,china \\ azkh@163.com, b18755548727@163.com, c2574544207@qq.com, \\ d1635483274@qq.com*Corresponding author
}

\begin{abstract}
Keywords:Complex geology, in-situ stress measurement, stress relief, geostress distribution Abstract.The Pakistan NJ Water Project is located in a typical Himalayan tectonic belt, the regional geological conditions are more complex,in order to understand the regional stress state distribution,stress measurement is carried out by stress relief method of hollow body.The three-dimensional stress state of six measuring points was obtained by field measurement,the measurement results show that:the overall stress in the region is high,the principal stress value increases linearly with depth,there is a large horizontal tectonic stress. The direction of the main stress shows a better consistency.
\end{abstract}

\section{Introduction}

With the gradual reduction and depletion of shallow resources, the depth of underground mining development is growing,due to the special environment in which the deep rock is located,the geological characteristics of deep rock mass 、 deformation mechanism、destructive features, they show a law different from that of shallow ones ${ }^{[1]}$. The problem of high ground stress is common in deep rock mass,Pakistan NJ project in the excavation process occurred strong rock burst ${ }^{[2]}$ and other issues.In order to reveal the geostress size and distribution characteristics of the engineering area,the initial stress distribution of the region is measured.

\section{Project Overview}

NJ water conservancy project is located in the northwest of the Himalayas, here the Himalayas are a series of parallel areas of the reverse fault(Salt ridge thrust layer SRT、Main boundary thrust layer MBT、Central thrust layer fault MCT、Main mantle thrust fault MMT)split into three distinct units(Himalaya mountains 、 Little Himalaya mountains and High Himalaya mountains).As shown in Fig. 1,the geological section, the layout of the structure and the layout of the measuring points, the collision between the Mesozoic and Late Cenozoic Indian plates and the Eurasian plate resulted in the southward squeeze, it develops these structures. The project is located in the Pakistani territory of the Himalayas, while the northern part of the Salt ridge thrust layer SRT is located in the sub-Himalayas, it consists of third Tertiary sedimentary rocks and Foreland Fold and fault molasse sedimentary rocks. The sub-Himalayan Mountains are constrained by the main boundary thrust fault MBT on the back ${ }^{[3]}$.

The tunnel formation is mainly the Tertiary Murre Formation,the surrounding rock is mainly composed of SS-1, gray sandstone and purplish red SS-2 powder with mudstone.Among them, SS-1 sandstone has "hard, brittle,broken" characteristics, the uniaxial compressive strength is above $160 \mathrm{MPa}$.

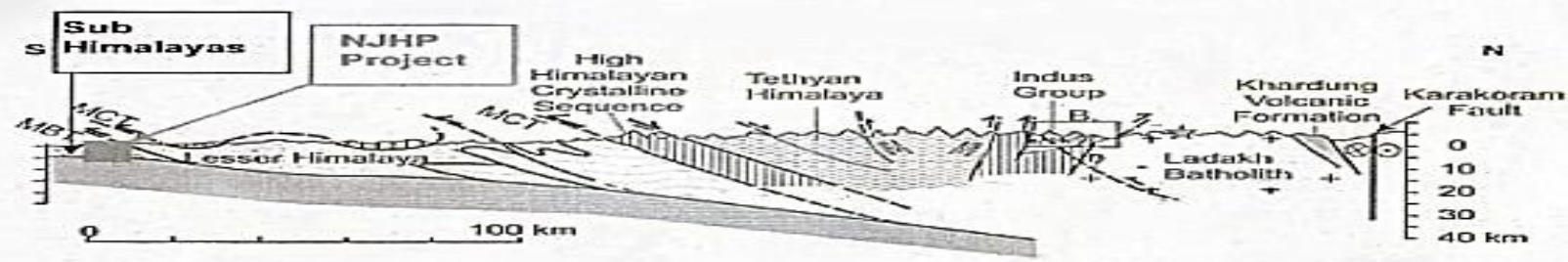

Fig. 1 Geological section of the northwest of the Himalayas 


\section{In-situ stress measurement}

The stress relief method is applied to the stress relief of hollow inclusion, the measuring element used is the $\mathrm{kx}-81$ type hollow body triaxial stress gauge ${ }^{[4]}$, the stress gauge in a single hole through a core release which can be obtained at the point of the three-dimensional stress state.After measuring several times through the hole,by using the least squares principle, it can get credible data.This method is easy to install and operate,the test success rate is high,the measurement accuracy is high,the experimental period is shorter,it can adapt to various geological conditions of rock mass, it is currently widely used in the world ${ }^{[5]}$.

In order to understand the regional stress state of the region,since 2015.6 2017.3, a total of 24 hollow inclusions were used in this project,it drilled 15 holes; three stress tests were carried out at $800 \sim 1785 \mathrm{~m}$ of TBM696 and TBM697 depth,and the stress test of 8 sections is carried out,data of 19 observation points were obtained,the choice of survey points basically avoid the stress concentration areas such as faults, fracture zones and the bending,turning and top of the chambers to ensure that the stress measurement point is located in the original rock stress area.9 of which were unable to perform stress relief tests or the data is inaccurate due to core cake and effluent,stress relief tests were successfully carried out on 6 other test holes.Fig. 2 is the layout of geological structures and measuring points.

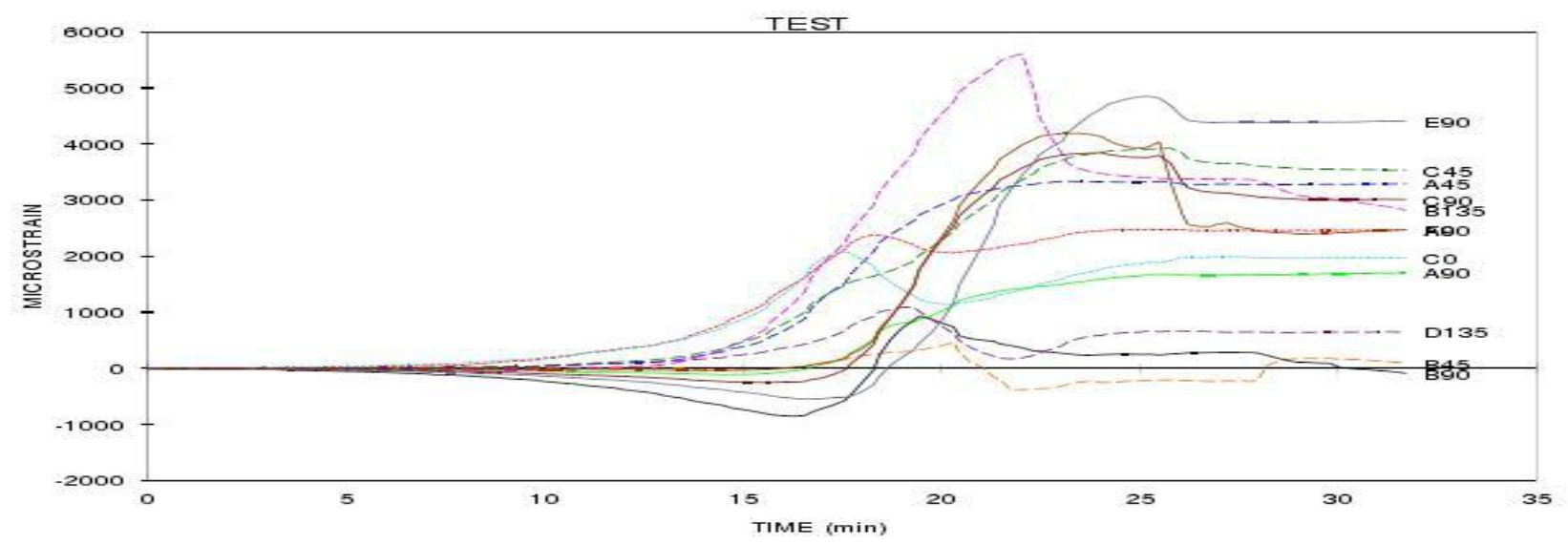

Fig. 2 Geological structure and measuring point arrangement

\section{In-situ stress measurement results}

Strain values and the modulus of elasticity and Poisson's ratioare are obtained from field measurements and core confining pressure test,they can be used to calculate the geostress value.By using the least square method, the optimal solution is obtained,then the magnitude and direction of the principal stress are obtained.The measured data of the six holes were calculated and analyzed,and the results of the in-situ stress test are shown in Table 1.

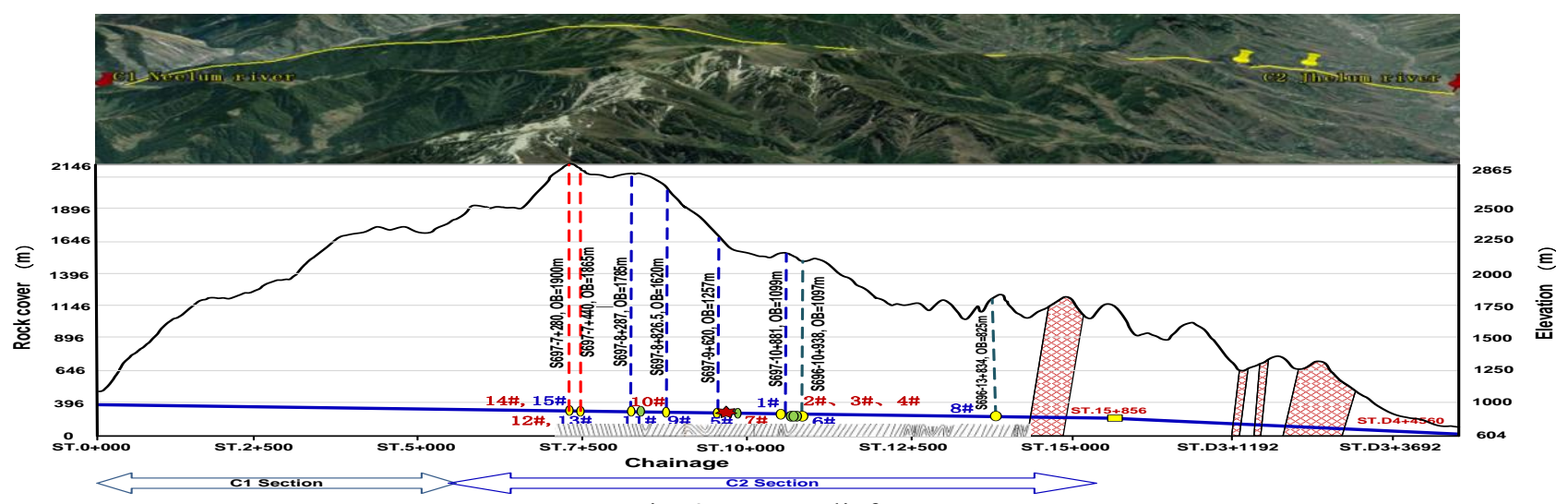

Fig. 3 Stress relief curve 
Table 1 Analysis of In - situ Stress Test Results

\begin{tabular}{|c|c|c|c|c|c|c|c|c|c|c|c|c|}
\hline \multirow[b]{2}{*}{ Location } & \multirow{2}{*}{$\begin{array}{c}\text { Burie } \\
\text { d } \\
\text { depth } \\
/ \mathrm{m}\end{array}$} & \multicolumn{3}{|c|}{$\sigma_{1}$} & \multicolumn{2}{|r|}{$\sigma_{2}$} & \multicolumn{4}{|c|}{$\sigma_{3}$} & \multirow{2}{*}{$\begin{array}{l}\sigma_{\mathrm{v}} \\
/ \mathrm{MPa}\end{array}$} & \multirow{2}{*}{$\begin{array}{c}\text { Elastic } \\
\text { modulus } \\
\mathrm{E} \\
/ \mathrm{GPa}\end{array}$} \\
\hline & & $\begin{array}{l}\text { value } \\
/ \mathrm{MPa}\end{array}$ & $\begin{array}{c}\text { Dip } \\
\text { angle } \\
/^{\circ}\end{array}$ & $\begin{array}{c}\text { Position } \\
/ 0\end{array}$ & $\begin{array}{l}\text { value } \\
/ \mathrm{MPa}\end{array}$ & $\begin{array}{c}\text { Dip } \\
\text { angle } \\
/^{\circ}\end{array}$ & $\begin{array}{c}\text { Position } \\
/{ }^{\circ}\end{array}$ & $\begin{array}{l}\text { value } \\
/ \mathrm{MPa}\end{array}$ & $\begin{array}{c}\text { Dip } \\
\text { angle } \\
/^{\circ}\end{array}$ & $\begin{array}{c}\text { Position } \\
/ 0\end{array}$ & & \\
\hline S696 St. $13+834$ & 800 & 50.7 & 14 & 271 & 24.3 & 43 & 206 & 19.5 & 44 & 358 & 29.7 & 42 \\
\hline S696 St.10+938 & 1010 & 68.6 & 32 & 312 & 33.5 & 47 & 195 & 24.4 & 37 & 70 & 34.5 & 52 \\
\hline S697 St.10+881 & 1040 & 80.5 & 11 & 330 & 37.7 & 47 & 224 & 25.8 & 25 & 75 & 32.7 & 42 \\
\hline S697 St.9+620.4 & 1200 & 88.9 & 2 & 297 & 42.8 & 60 & 203 & 27.1 & 30 & 29 & 44.2 & 50 \\
\hline S697 St. $8+826.5$ & 1530 & 53.4 & 14 & 300 & 51.7 & 5 & 339 & 43.2 & 75 & 227 & 43.9 & 35 \\
\hline S697 St. $8+287.1$ & 1785 & 109.2 & 20 & 269 & 67.2 & 60 & 36 & 36.2 & 22 & 170 & 62.6 & 67 \\
\hline
\end{tabular}

From the data of six measuring holes, it can also be found in the NJ project area deep ground stress distribution exists the following laws:

Distribution of principal stress, the area of the overall stress value is higher,the hard and brittle SS-1 sandstone in this area is hard and dense, it will be easy to deposit a higher elastic strain energy, so there is the rock burst geological conditions, and pre-construction process occurred the rock burst phenomenon several times just illustrates this point. When the measuring point of St. $8+826.5$ of the stress is relieved,the borehole has been running out of groundwater all the time,because of the development of the fissures is near the surrounding rock and the aquifer, the pore medium and the bearing capacity play a certain role in the release of the original geostress, which changes the stress distribution,resulting in abnormal ground stress distribution low.In fact, the value of the exception will be removed,the regression analysis method was used to fit the stress of the measured points, and the relationship between the principal stress and the vertical stress can be obtained with the depth: $\sigma_{1}=0.0532 \mathrm{H}+15.813, \quad \sigma_{2}=0.0428 \mathrm{H}-8.8519, \quad \sigma_{3}=0.0158 \mathrm{H}+8.0461, \quad \sigma_{\mathrm{V}}=0.0343 \mathrm{H}+0.3101$.

In the formula, $\sigma_{\mathrm{V}}$ represents the vertical stress of the measuring point, and $\mathrm{H}$ is the vertical distance from the measuring point to the surface.

It can be found under normal stress distribution conditions, with the increase in depth,vertical stress and horizontal stress increase linearly.The linear coefficients are 0.0532,0.0428, 0.0158 and 0.0343 respectively,which means that the depth of each increases $100 \mathrm{~m}$,stress will increase by $5.32,4.28,1.58$ and $3.43 \mathrm{MPa}$ respectively. The maximum principal stress, the intermediate principal stress and the vertical stress are greater than the gravitational stress in the ideal state of $2.7 \mathrm{MPa}$ (take the overburden density $2700 \mathrm{~kg} / \mathrm{m}^{3}$ ). Which shows that the geostress is obvious by the geological structure,there is a large horizontal tectonic stress in this region,the excavation of the tunnel will have an important impact on it.

The maximum principal stress orientation, it can be seen from Table 1, the direction of the maximum principal stress exhibits a better consistency, the azimuthal variation ranges from 270 to $330^{\circ}$, the average is $296^{\circ}$, the dip angle is between -30 and $30^{\circ}$. While the tunnel azimuth is $38^{\circ}$,so most of the measuring points of the maximum principal stress orientation and the vertical tunnel axis are vertical.That is,most of the maximum principal stress directions are not parallel to the plate movement,but it is perpendicular to the direction of movement of the plate. The reason for the analysis is maybe that:the area is located in the typical Himalayan tectonic belt,plate motion during Mesozoic and Cenozoic periods is intense,and with more complicated geological conditions, the local restraint makes the formation distorted,which results in a great deal of shear stress,and thus it change the direction of the main stress. The distribution of stress in China's 
Qinghai-Tibet Railway can also fully reflect this point ${ }^{[6]}$.

\section{Conclusion}

Through the field stress measurement,combined with the NJ area engineering geological survey,put forward the following points.

(1)The region belongs to the high ground stress region, and there is an extremely high stress state in some areas, and the Rock conditions are associated with rock burst.

(2)The principal stress is basically linear with the depth,and it is related to domestic and international statistical data ${ }^{[7]}$.

(3)The direction of the maximum principal stress is basically perpendicular to the direction of the tunnel axis,measures should be taken to reinforce the surrounding rock mass at any time.

(4)In order to prevent the occurrence of rock burst,it is necessary to strengthen the monitoring and comprehensive analysis, especially in the key parts to strengthen the stress monitoring.

(5)Reasonable construction speed and method are helpful to prevent rock burst during construction.

\section{Reference}

[1] Heping Xie.The concept and expectation of deep rock mechanics and mining theory[J]. Engineering Science and technology, 2017,49(2): 1-15.

[2] Qiong Chen, Enyu Chen. Rock burst Analysis of Tunnel TBM Construction under High Ground Stress[J]. people Yangtze River, 2016, 47 (7): 64-67.

[3] lqbal M.Sheikh.Pakistan.Van S.Williams.Environmental geology of 1slamabad-Rawalpindi area,northern Pakistan[R]. Pakstain:Gen-logical Survey of Pakistan.

[4] Huichun Gao,Shengli Yang and son on. Test method and engineering application of in-situ stress in hollow inclusion [J]. Coal engineering, 2015, 47 (4): 83-89.

[5] Hegang Qi, Zhou Gang. Study and application of in-situ stress measurement technique for hollow inclusion[J]. Coal safety, 2016, 47 (12): 141-144.

[6] Zhentao Wang. The geological characteristics and evolution of the Qinghai Tibet Plateau [J]. Science and technology review, 2017, 35 (6): 51-58.

[7] Peng Li, Shengjun Miao. Analysis and application of measured crustal stress in Chinese metal mining area [J]. Engineering Science, 2017, 39 (3): 323-334. 